\section{¿CÓMO PREPARAR LAS CONDICIONES REMOTAS PARA LA RESPUESTA VOCACIONAL SEGÚN EL CORAZÓN DE DIOS?}

Autor: Francesco Lambiasi. Consiliario General de la Acción Católica y Obispo de Anagni-Alatri.

Traducción de Alonso Morata.
El autor, comienza aclarando que "remotas" no se opone a "concretas", sino a "próximas", dándole el significado de findamentales. Se pregunta si estamos en la cultura del hombre sin vocación. Dos ejemplos, Kundera y Vattimo, la figura de Narciso, el culto a la belleza, a la moda, Pinocho, etc. avalan esta visión. No obstante encuentra elementos positivos: sentido de la dignidad de la persona, autenticidad, proximidad. El artículo explicita lo que significan las tres acciones que sustentan una cultura vocacional: convocar; provocar; invocar.

La palabra sobre la que debemos ponernos de acuerdo desde el principio es ese adjetivo que aparece detrás de "condiciones", 'Cómo preparar las condiciones remotas...". Me temo que a alguno esta palabra pueda traerle la idea de algo aéreo, abstracto, como si esta mañana nos tocase estar en la terraza contemplando los sistemas planetarios... En verdad 'remotas' no se opone a 'concretas', sino a 'próximas', condiciones específicas, inmediatas. Por consiguiente tomo remotas en el sentido de fundamentales: ¿cuáles son las condiciones fundamentales, o sea radicales, para que se pueda favorecer una cultura vocacional, por lo tanto para una respuesta vocacional según el corazón de Dios? Esto está en la línea de la Novo Millennio Ineunte y de las Orientaciones Pastorales de los Obispos para este decenio. Los dos documentos, como sabemos, dedican gran parte, la primera, la fundamental, a la contemplación. Me parece que hay en nuestra Iglesia un déficit no 
tanto de organización, cuanto de contemplación. En esta perspectiva contemplativa quisiera intentar responder a esta pregunta.

Antes, sin embargo, quisiera manifestar mi pensamiento sobre una pregunta que pienso que ya (ayer por la tarde) habéis tenido ocasión de afrontar. La cultura de la sociedad postmoderna, considerada ampliamente, ¿se puede considerar vocacional? El Documento Final del Congreso sobre las Vocaciones al sacerdocio y a la vida consagrada en Europa, que tuvo lugar en Roma del 5 al 10 de mayo de 1997, con el título Nuevas Vocaciones para una nueva Europa, hablaba de 'hombre sin vocación'. En efecto, en una lógica de autorrealización, en donde el horizonte del futuro se reduce, para tantos jóvenes, "a la situación económica, o a la satisfacción sentimental y emotiva", dice textualmente este documento, "como si el modelo antropológico prevalente fuese el de un hombre sin vocación" (11c) Una afirmación molesta, que podría hacernos formar parte también a nosotros de los euroescépticos, y de todos modos una afirmación que podríamos apoyar fácilmente con una avalancha de datos estadísticos, pero quizás resulten más elocuentes dos citas. La primera la tomo de una novela (que me parece hace años) fue muy leída, de Milan Kundera, La insoportable levedad del ser. Al final de esta novela, la protagonista, hablando con su marido, un cirujano que ha tenido que abandonar el hospital, dice con pena al marido: "Tu misión era la de operar". Y la respuesta del marido es significativa y resume en parte todo el sentido de la obra: "Teresa, una misión es una cosa estúpida. Yo no tengo misión alguna. Ningún hombre tienen una misión. Y es un alivio enorme descubrir que estás libre de tener una misión”. ¡El hombre sin vocación! Entendemos enseguida que detrás de esa afirmación está la filosofía del pensamiento débil... Uno de sus máximos exponentes. Gianni Vattimo, en una entrevista, a la pregunta sobre la tarea de la filosofía respondía: "Creo que la filosofía no debe ni puede enseñar hacia dónde se tienen que ir, sino a vivir en la condición de quien no se dirige a ninguna parte". Por consiguiente: ninguna meta, ninguna misión, ninguna vocación.

¿A quién vamos a comparar esta generación? (cf Mt 11, 16). Antes de entrar a analizar tablas y tablas de datos estadísticos, por otra parte fundamentales para no andarnos por las nubes, voy a referirme a una figura mitológica: Narciso. Me parece que este hombre sin voca- 
ción puede ser contemplado en la figura de Narciso, (este) héroe de la mitología griega, condenado por los dioses a enamorarse de la propia imagen. La muchacha a la que ama Narciso, tienen un nombre emblemático: Eco. Es el eco de Narciso y Narciso por eso está siempre replegado sobre sí mismo. Sabemos cómo terminó la historia: Narciso, un buen día, mirándose en el espejo de las aguas heladas de un lago, ha sido presa de un ataque de 'narcisismo' y por el deseo de abrazarse se zambulle en esta agua y allí se ahoga.

Signos del hombre narciso en nuestra sociedad: basta ver la celebración obsesiva de la belleza corpórea, el culto a los estados símbolo, de la moda con su subsiguiente encantamiento de hacer significativo lo insignificante; o, por otra parte, el rechazo de la enfermedad, de la vejez, del defecto físico. Pero pensemos también en la búsqueda de gratificación y de aceptación. Quizás, además de a Narciso, nos podemos referir a Pinocho, el hombre niño, inseguro y arrogante, con su frenético afán de divertirse, de jugar, con la absurda pretensión de realizarse, prescindiendo del padre, sin embargo llamado a ser hijo. No obstante no me atrevería a tildar la cultura, nuestra cultura, como antivocacional -a parte de que hay que preguntarse, con cierto desencanto, si alguna vez ha existido una cultura vocacional...- porque hay varios elementos sin duda positivos. Por ejemplo el sentido de la dignidad de la persona humana, poder existir en la propia autonomía, fuera de las soluciones prefabricadas y de las herencias preestablecidas; el deseo de autentici$d a d$, con la búsqueda de sentido y la necesidad de dar un significado original a la propia vida; el deseo de proximidad, de sociabilidad, de encuentro, de solidaridad, de paz ( $\mathrm{cf}$ CV 37). Podremos decir: la subjetividad y la alteridad. El problema está en conjugarlos juntos, porque si estas dos cosas no se ponen unidas no es posible asegurar una condición remota, fundamental para una cultura vocacional. Todo el problema está en el conjugar juntos estos fermentos haciendo síntesis entre la búsqueda de autenticidad y la aceptación de la alteridad, sobre todo es necesario dar profundidad a estos elementos, purificándolos de incrustaciones ambiguas y abriéndolos a la transcendencia.

Esquematizando, pienso que una comunidad cristiana que quiera favorecer una verdadera cultura vocacional debe garantizar tres acciones fundamentales que corresponden a otros tantos verbos: convocar, provocar, invocar. 


\section{Con-vocar}

La Iglesia, lo sabemos, es la "asamblea santa". Este es el primer verbo vocacional. Porque la Iglesia refleja y participa toda ella de la con-vocación trinitaria. S. Cipriano, citado en Lumen gentium, afirma a propósito de esto: El sacrificio más agradable a Dios es nuestra paz, nuestra concordia, nuestra reconciliación y la convocación a la unidad del Padre, del Hijo y del Espíritu Santo. La Trinidad como fuente y como desembocadura, como la fuente primera, la medida más alta y la meta última de todo nuestro camino. Es importante que la Iglesia indique este sol trinitario, tenga siempre el índice dirigido, la mirada puesta en lo alto. En la Trinidad vemos las personas en una relación totalmente estrecha entre ellos, de manera que podemos afirmar que no sólo cada persona tienen una relación con la otra, sino que es relación con la otra. El Padre no está replegado de forma egoísta sobre sí mismo, sino que está totalmente abierto al Hijo y con el Hijo se encuentra en el Espíritu Santo; por lo que podemos decir que las preposiciones son con, por, en, porque cada persona está con la otra, en la otra, por la otra.

El descubrimiento del misterio trinitario se aproxima al descubrimiento de la Iglesia como comunión, como convocación. Siendo Dios una comunión de personas, entonces la forma de vida que mejor expresa esta comunión en la tierra es la Iglesia, en la que las personas, dos o tres o más están en comunión, viven con un corazón y un alma sola.

Ha habido un tiempo, un largo tiempo, en el que el misterio trinitario se veía en clave sobre todo intrapersonal: recordamos el Espíritu como 'dulce huésped de las almas'; son perspectivas que han formado santos, ciertamente se trata de alguien dulcísimo y muy consolador, sin embargo hemos llegado al momento de pasar de la dimensión intrapersonal a la dimensión interpersonal, de lo íntimo a lo comunitario, del yo al nosotros, es ésta la que el Papa llama 'espiritualidad de comunión'.

Releo un pasaje que además conocemos casi de memoria, de la Novo Millennio Ineunte, 43: "Antes de programar iniciativas concretas, es preciso promover una espiritualidad de comunión", -condición remota fundamental- "haciendo emerger como principio educativo en todos los lugares en los que se configura el hombre cristiano, en los que se educan los ministros del altar, los consagrados, los responsables pastorales, donde se forman las familias y la comunidad". 
Por eso, espiritualidad de comunión significa instaurar, con la gracia del Espíritu Santo, relaciones marcadas por el modelo trinitario, según esas tres preposiciones que hace un momento he indicado; no los unos sin los otros, los unos sobre los otros, los unos contra los otros, sino los unos con los otros, por los otros, en los otros.

Siempre en el mismo pasaje el Papa continúa: "Espiritualidad de la comunión es hacer espacio al hermano, llevando unos las cargas de los otros y rechazando las tentaciones egoístas que continuamente nos asedian y generan competencia, emulación, desconfianza, celos". Estos son virus anti-vocacionales y es preciso por eso que la comunidad los tenga siempre presentes (porque), de otra manera (luego) no viven esta espiritualidad de la comunión.

Pues la Iglesia es -decía Tertuliano- "el cuerpo de los Tres". Ésta es la perspectiva ideal.

¿Y cuál es la situación real? La situación real es que somos minoría. Esta situación no es ni una culpa ni una elección, es un hecho y por tanto, ante este hecho no cabe ni victimismo ni triunfalismo, ni lamentaciones ni aplausos. Porque también la Iglesia minoritaria tiene sus tentaciones. Señalo dos. La de ser una Iglesia-secta, en la cual la relación de pertenencia viene absolutizada a espensas de otras relaciones; o bien, segunda tentación, Iglesia élite, una Iglesia de los puros, sea en sentido moral -por lo cual no hay espacio para los pecadores-, o en sentido intelectual -quienes no saben hacer las moniciones en la Liturgia de la Palabra son de serie B o C-. deberíamos recordar que también los pecadores, los lejanos, los desocupados pertenecen a la Iglesia (Lumen gentium 14). Se está en la Iglesia no solo para convertir sino, antes que nada, para convertirse.

Permitidme ahora partir una lanza a favor de aquella institución que, tantas veces, nosotros en Italia corremos el riesgo de dar por liquidada, pero que a veces desde fuera nos envidian: y es la parroquia sin más. La parroquia es la Iglesia de todos, también de los no practicantes, es la estructura de base que ofrece a todos la posibilidad de una pertenencia eclesial con la sola y exclusiva condición del bautismo y del no rechazo explícito de la fe.

En una artículo muy lúcido y también provocador, Severino Dianich, en Vita pastorale de abril del 98 (pp. 36-39), se hacía una pregunta: ¿Parroquia sí, parroquia no? Y decía: "Estemos atentos, por- 
que corremos el riesgo de cambiar radicalmente la pastoral en la vida de la Iglesia". También los movimientos, los grupos tienen necesidad de la parroquia. Porque de otro modo cuando uno sale del movimiento o del grupo, corre el riesgo de salirse de la Iglesia. ;Esto no! En la Iglesia no se entra por pertenecer a un movimiento o a un grupo, sino porque eres bautizado. Esto debemos recordarlo siempre.

Sin embargo, para que la parroquia sea efectivamente la "casa de la comunión", no puede reducirse a ser la parroquia del "azar": por azar habitamos aquí y por esto pertenecemos a esta parroquia; o la parroquia de las "cosas": las cosas que hay que hacer, la actividad, las iniciativas: se requieren al menos dos condiciones que considero esenciales.

\section{Una comunidad ministerial}

Es necesario ante todo pasar de una Iglesia clerical a una Iglesia ministerial, en la que la unidad de la misión se expresa en la variedad de los ministerios, no en la concentración de poderes. La imagen más evocadora que presenta bien esta realidad de la parroquia-casa de la comunión, es la de la iglesia-coro. San Ignacio de Antioquia dice textualmente en la carta a los efesios: "Cada uno de vosotros se las arregle para formar coro. En el coro no canta solo el maestro, antes bien, el maestro no canta, hace cantar, y debe hacer cantar a todos, la misma partitura, la misma melodía". Esta Iglesia-coro se realiza si se cultiva hasta el máximo la espiritualidad de la unidad, o sea ¡la espiritualidad de la comunión!

Permitidme que lea un breve pasaje de san Bernardo, en un discurso sobre el Adviento, meditando sobre el triple infierno afirma: "El demonio teme poco a los que ayunan, a los que oran incluso de noche, a los que son castos, porque sabe bien a cuántos de estos ha llevado a la ruina. Pero sí que teme: a los que están unidos de corazón y viven en la casa del Señor con un solo corazón, unidos a Dios y entre sí en el amor, estos producen dolor al demonio, temor y rabia. Esta unidad de la comunidad no sólo atormenta al enemigo, sino que atrae también la bendición de Dios, como él mismo atestigua en el Cantar de los cantares: 'Has herido mi corazón, hermana y esposa mía...'

He aquí la unidad, la espiritualidad de la unidad. Ahora concretamente debemos decir no al individualismo y no al centralismo. El indi- 
vidualismo se verifica cuando cada uno quiere ser el todo. El centralismo al contrario, cuando uno quiere ser todo. Entonces, el individua-

lismo divide y separa, forma el hielo. El centralismo las más de las veces sofoca y absorbe. Se puede morir ya sea aterido ya sofocado por el excesivo calor. Se trata de los verdaderos y propios pecados contra el Espíritu de Pentecostés que por el contrario unifica y diversifica, articula y recoge, abre y concentra.

\section{El ministerio de la síntesis}

La segunda condición de posibilidad para que se verifique esta Iglesia-coro: es preciso decir no al párroco manager, al párroco líder, al párroco supertécnico de la pastoral. Su deber no es el de organizar o remover; es el de hacer caminar. Porque -decían ya los obispos italianos en el 1977- el párroco no tiene la síntesis de los ministerios, pero tiene el ministerio de la síntesis. Entonces, en estas condiciones la comunidad puede hacer encontrar un Cristo vivo, no sólo en el tabernáculo -porque incluso la comunidad más depauperada tiene al menos este tesoro, la Eucaristía-, sino un Cristo vivo en cualquier grupito aunque sea delgado y maltrecho, que es el grupo de cristianos que sienten la llamada a dar figura corporal a la presencia de Cristo Señor.

Por tanto y en resumen, convocar significa, para una comunidad cristiana, asegurar tres características que ya he señalado y que ahora recuerdo.

En primer lugar la unidad. Pero, diría san Pablo, no la unidad psíquica, sino la pneumática, o sea la unidad espiritual, una unidad que no se mide por la temperatura del calor del abrazo en el signo de la paz, sino -como dice el papa- por hacer espacio al hermano, llevar los unos las cargas de los otros, dar la vida, dar el tiempo, proporcionar estima, respeto.

Segundo, la humanidad. Cristo Señor se ha hecho reconocer como hijo de Dios, viniendo en medio de nosotros no como un ángel -no ha hablado la lengua de los ángeles- sino como hombre. Tanto de él como de sus cristianos se debería decir: Humanos de esta manera sólo saben serlo los cristianos. ¡La humanidad! ¿Por qué tanta gente se va decepcionada de nuestras comunidades? A menudo es por esto, porque tenía un problema y el párroco estaba allí nervioso, y ha dado una 
mala respuesta. Leed el artículo de don Marco Trivisone sobre Vocaciones. Cuantas veces la gente permanece de esta manera, asustada por culpa de una mala respuesta. No se trata sólo de garantizar algo más de espíritu de delicadeza, en nuestras parroquias, sino la humanidad, la humanidad fundamental.

Tercero: la alegría. En el profeta Isaías se recoge una provocación que viene de los paganos que dicen a los israelitas: "Mostradnos vuestra alegría". Porque la alternativa a la alegría es el tedio. Y también aquí es trágico ver a los jóvenes que se nos van no dando un portazo, sino bostezando. Porque uno que discute antes o después acaba por poder volver, pero uno que se va bostezando es muy difícil que vuelva.

Pues, ante todo, una comunidad está llamada a convocar. A dejarse convocar y a convocar. A abrirse. Debería ser en pequeño un poco la plaza de san Pedro, la columnata de Bernini: estos brazos maternos de la Iglesia que no sofocan, que acogen pero dejan siempre la posibilidad de entrar y de salir. Porque la Iglesia no es un cuartel, no es una empresa.

\section{Pro-vocar}

Provocación que tomo tanto en el sentido común del término, como desafío, como también en el sentido bíblico de profecía.

\section{Una comunidad es capaz de provocar}

Cuando está enamorada de su Señor. Una comunidad enamorada de Jesús que es capaz de hacer entender que el centro es Él, que todo aquello que existe en la Iglesia, desde las funciones de las personas hasta los sacramentos, las oraciones, la organización, las propiedades varias y la tradición es por Jesús. En el centro está Él. Encuentra en Él las motivaciones, la base, el fin, la razón fundante. Esto es importante porque es Él el que llama. Es Él el que se dirige al joven o a la joven personalmente. Es Él, no las tradiciones, la propiedad, las posesiones, el deseo, la compasión, el gusto, el compartir algunos modos de vivir. Estas pueden ser imágenes que nos captan, pero no serán jamás el motivo de la decisión. Esta propuesta insistente permite orientar directamente al centro de la decisión toda la colección de dudas, incertidumbres, seguridades inconstantes, momentos de indecisión. 
Una comunidad es capaz de provocar cuando responde al deseo de felicidad de los hombres. La Iglesia existe para la felicidad de los hombres, no sólo para el más allá, porque si no nuestro Señor podría haberse ahorrado el descender en medio de nosotros, podría haber mandado a un ángel o hacer colgar una cuerda desde lo alto y después "que se agarre el que pueda". La Iglesia existe para la felicidad de los hombres, para su paz, para la belleza, no para el hastío, para el deber, para el orden, para la disciplina, para la moral. La fe debe dar sabor a la vida y la Iglesia es la comunidad de quienes quieren dar sabor a la vida; y Dios llama a los jóvenes a ponerse junto a él para emanar ese gusto de la vida. Sacerdotes contentos de vivir, religiosos entusiastas, religiosas felices son mucho mejor que todas las mesas redondas y videocasetes de tema vocacional. Sacerdotes y hermanas que viven su vocación como tales y no como tapa-agujeros organizativos. Las experiencias de renovación de la propia congregación religiosa y una redefinición coherente del propio carisma son condiciones necesarias para proponer opciones de especial consagración.

Una comunidad es capaz de provocación cuando es capaz de experiencias radicales de vida cristiana. También experiencias algo transgresoras de la rutina de la vida cotidiana. La vida cristiana no es un concentrado de buen sentido, sino una dedicación sin reservas a una causa, es una pasión. El único modo de ser cristiano es comprometerse con una causa, que es la de amor, la de la dedicación, la del servicio. Son ahora útiles las experiencias de vida común, en las que nosotros podemos desinfectarnos de la enyesadura de los padres o de los amigos.

Cuando esta comunidad tiene el valor de pedir mucho, de pedirlo todo. El valor de atreverse a pedir en los lugares más impensados de la vida del joven. La vocación a la vida consagrada es un acto contracorriente y a menudo resulta más allí donde la corriente se ha hecho camino obligatorio hacia la insignificancia, la banalidad, la muerte de las aspiraciones más bellas.

\section{Dar algunos pasos}

Pasar de la lógica del mérito a la lógica del don. Vivíamos en una sociedad fuertemente meritocrática que ha perdido el valor de la gratuidad. $\mathrm{Y}$ en esto capitalismo y materialismo y marxismo acaban por 
converger, aunque sea por motivos opuestos. Uno haciendo del dinero el resorte de la vida y el otro relegando lo gratuito a fábulas para niños. El economicismo exasperado que mira más las profesiones que las ocupaciones es un rasgo marcado de nuestro occidente opulento y desesperado. Nuestra generación está dilapidando el ahorro de las generaciones precedentes y está despilfarrando los recursos del mañana. Y debemos recordar que todo esto comporta una alta tasa de violencia. Esta nuestra sociedad es muy violenta. Es una sociedad en la cual siempre hay razones para que venza y venza siempre el más fuerte. Miestras la lógica evangélica no es la farisaica del mérito, es la lógica del don, de la gracia: todo es gracia (Rom 9, 16; 1 Cor 4, 7). Santa Teresa de Lisieux subraya a este propósito: la vida cristiana "no es cuestión de voluntad, ni de esfuerzos del hombre, sino de Dios que usa de su misericordia". Todo es gracia. De nuevo Teresa de Lisieux: "El mérito no consiste en hacer ni en dar mucho, sino más bien en recibir, en amar mucho". ¡En recibir! Y ella que entendía, dice: "Jesús dice que hay mayor alegría en dar que en recibir, pues dejémosle a él la gloria del dar, a nosotros la de recibir". Por tanto es necesario decir también aquí los noes. No al perfeccionismo ilusorio y frustrante, no al voluntarismo espasmódico y desesperante. Sartre decía: "Es necesario haber experimentado el amor antes que la moral, de otra manera hay dolor". No para decir sí. Sí a la gratuidad y al compartir: todos somos bastante ricos como para poder dar, lo suficientemente pobres para poder recibir. Es necesario que la comunidad cristiana recupere el valor de la gratuidad y de las cosas inútiles, del contemplar sobre todo. El óbolo de la viuda, los pobres son nuestro tesoro; pobres de cultura, pobres también de espiritualidad cultivada, gente que jamás ha hecho cursos, ni ha estado en congresos, sin embargo nos precede a años luz en el camino del Reino. El más pequeño movimiento de amor -este es Juan de la Cruz- es más útil a la Iglesia que todas sus obras puestas juntas. También lo cita Teresa de Lisieux tres veces. El valor de la oración sin preocuparse de verificar si hemos sido o no oídos. Así pues orar por las vocaciones sin ponerse a contar... es dejarse manejar por amor, dejarse "deshojar" -y continúa Teresa de Lisieux-: ¿Qué sería de la Iglesia si su agenda estuviese llena de compromisos, de actividad caritativa, si su bolsa estuviese llena de dinero para los pobres, y la casa de Betania estuviese sin el perfume del amor?". 
Segundo paso: de la lógica del proyecto a la del seguimiento. El narcisismo empuja a la autorrealización. El proyecto. Pero la vocación no es elegir, es ser elegido, es dejarse elegir. El cristiano no piensa en salvarse, en realizarse, y la comunidad cristiana no tiende a defenderse o a afirmarse. Es el discurso de los testimonios vocacionales fundamentales, que deberían ser asegurados en todas las comunidades cristianas, también en aquellas en las que son mayoría las hermanas entradas en años... ¿por qué los jóvenes no pueden entrar en contacto con una comunidad religiosa?

Testimonios dados por sacerdotes que viven una existencia serena, grata y satisfecha. Antes de Navidad me han regalado una novela, escrita por un sacerdote que no conozco, Luisito Bianchi, que me dijeron que era capellán de la comunidad monástica de Viboldone, La misa del hombre desarmado. Os transmito la conversación entre un ex novicio y su anciano párroco. Hablan del hermano de este ex-novicio, que es un joven médico que fue a la guerra de Grecia y que está en peligro de que le amputen las piernas porque ha dado sus calcetas de lana, que le había mandado su mamá, a sus compañeros que tenían más frío que él. Pero no va a la iglesia. Entonces el ex-novicio dice al párroco: "Mamá está muy preocupada por Piero, porque Piero no va a la Iglesia. Mamá dice: "Si Piero debía cambiar, ¿hubiera sido mejor que hubiera continuado yendo a la iglesia, cerrando sus manos agujereadas? Sólo Dios lo sabe..." y he aquí la respuesta del párroco: "Para conocer a las persona, querido, no es necesario vivir a su lado, es suficiente quererles bien y tratar de captar sus reacciones y sus opciones. Ciertamente es necesario quererles bien, de otra manera no se entiende nada; no digo amarles, que es mucho más comprometido" -¡la retórica del amor!-, "quizás presuntuoso, pero quererlos bien". También aquí el arcipreste manifestaba la medida que empleaba en el beber en un vaso o en el leer un canto de la Divina Comedia". Y vuelve a decir: "A Piero lo he visto nacer, lo he bautizado, le he dado el catecismo, ha crecido lentamente, sin prisa, en mi ánimo. Como ha sucedido contigo. He visto a tu padre cuando buscaba a tu madre con la mirada en los bancos de las jóvenes, durante la misa mayor. Los he casado, ¿cómo no quererlos bien? No es necesario que vosotros os deis cuenta de ello. Si se va por el mismo camino se crece unidos; y un sacerdote, si no ha estado atento a este crecimiento, ¿qué sentido podría dar a su vida?" 
Pero, responde el ex-novicio, hermano de Piero: "¿Y si el crecimiento no se desarrolla según su deseo"? "Mira querido", responde el anciano sacerdote "hay tiempos y modos de crecimiento que el sacerdote no conoce ni puede conocer. No debe sentir ninguna amargura si no corresponden a sus tiempos. Su querer bien no sustituye al amor de Dios, y aquí es necesario propiamente hablar de amor" -este término lo reserva con pudor para el amor de Dios-. "El amor de Dios conoce lo que hay en Piero, no puedo hacer otra cosa que adorar este amor. La amargura y la desilusión no son indicios de una buena adoración. Cierto, cierto -me previene- se puede tener un sufrimiento si se constata una infidelidad, según nuestros parámetros, en el don de Dios, pero jamás la amargura o desilusión. Por otra parte es el mismo sufrimiento que experimentamos al constatar nuestra infidelidad".

Testimonios vocacionales, pues, ofrecidos por sacerdotes; por laicos comprometidos en la coherencia con el evangelio, sin que la coherencia genere angustia. Tú no vas a anunciar tu vida, sino la muerte y la resurrección del Señor. Sólo puedes decir: ¡Él me ha salvado! Esto puedes decir, no lo que tú has hecho. Religiosas y religiosos que no dan la cara diciendo, como decía Madre Teresa, "Hay hermanos, hermanas, consagrados que dan vueltas a tu alrededor poniendo una cara, como si dijeran: "¡Mirad lo que me han hecho!" Y una cosa es cierta, la angustia por las vocaciones produce angustia, no produce vocaciones.

Tercer paso: de la lógica de la idolatría a la lógica de la eucaristía. Se me ocurre a menudo citar un pasaje de Bonhœffer que es profético. Dice Bonhœffer: "Lo contrario de la fe no es la incredulidad, como nosotros pensamos; es la idolatría". Sabemos lo que es un ídolo; el ídolo no es tanto la estatuilla, de madera o de mármol o de oro, es la prolongación de mi yo. Sería necesario descubrir de nuevo a Feuerbach, que lo ha adivinado; ha errado sólo en el decir que así nace el dios verdadero. No, así nace el ídolo.

Algún día me rondaba la cabeza hojear las Fuentes Franciscanas. En la Leyenda de los tres compañeros se da una pincelada sobre la conversión de san Francisco, de este modo: "Después del beso al leproso, en aquel momento Francisco cesa de adorarse a sí mismo". Esta es la idolatría. Esto es el narcisismo.

Hace algunos años Eugenio Scalfari publicó una novela, titulada Encuentro con el Yo. Este yo que, según el autor, crea Dios a su propia 
imagen y semejanza. Y dice así: "Esta majestuosa presencia divina no es otra cosa que los espejos construidos en el Yo a fin de que reflejen las refracciones prismáticas que la mente distintamente está en grado de filtrar". Entonces, el autor conduce un diálogo interesante con "orejas narcisas", esto es, se escucha a sí mismo, y se siente al fin, que está "solo sobre un tren desierto: en las estaciones hay gente, luces, algunas veces alegría. Pero de pronto sale de nuevo, no se sabe por qué, no se sabe dónde".

Es necesario pasar de la idolatría a la Eucaristía. Porque en la Eucaristía tenemos el máximo de descentramiento, es Dios, que en cierto sentido florece en sí, es Cristo el que se hace pan y el que dice : "Tomad". No dice: "Yo os doy", "Tomad, comed; tomad, bebed". Todo es gracia. A la gracia de Dios debe corresponder la gracia del hombre, esto es la Eucaristía, la gracia (Cf 1 Cor 1, 4; Ts 5, 18). Cuando san Pablo dice: dad gracias en toda ocasión (eucaristeite) - escribe Pablo- y tiene el sentido en la Biblia de dad gracias. Podríamos muy bien traducir por "haced eucaristía". No los quejidos, la pastoral de la lamentación, por los tiempos funestos de muerte de la fe y de la impiedad triunfante, sino la gratitud, el agradecimiento. En el documento Nuevas vocaciones para una nueva Euro$p a$, en el $\mathrm{n}^{\circ} 36$ hay una bella página sobre la vocación como agradecimiento, como eucaristía. A ella os remito para ulteriores ahondamientos.

\section{In-vocar}

En el doble sentido: en el de orar, o en sentido más existencial de pedir ayuda.

\section{En sentido litúrgico}

En primer lugar orar, ya que toda vocación nace de la invocación (NVNE 27a). No se trata sólo de hacer oraciones por las vocaciones, sino de vivir la oración, la gran oración, la liturgia como el lugar del anuncio y de la realización vocacional. El año litúrgico es estructuralmente itinerario vocacional: es la celebración de la historia de la 1lamada de Dios y de la respuesta de la Iglesia․ Nuestros jóvenes viven

${ }^{1}$ Cf M. SODI, "Vocazione", in Dizionario di omiletica, p. 176. 
en esta tierra, en esta Iglesia, con un año litúrgico que comienza el primer domingo de Adviento y acaba con la fiesta de Cristo Rey. Caminamos; ahora se trata de ayudarles a caminar, esto es el acompañamiento vocacional, esto es el discernimiento. Ayudarles a verse reflejados en la historia de Israel, de la Iglesia, de Cristo. Cristo es la vocación, porque Él es el sí de Dios al hombre y del hombre a Dios. El tiempo pascual como celebración de la vocación y misión de Cristo, el tiempo de Navidad con el Adviento es el tiempo de la expectación y de la venida del Señor, el tiempo ordinario como camino de configuración a Cristo, con el sí de Dios al hombre y del hombre a Dios.

\section{El sentido existencial}

Invocar también en sentido existencial. Cito a Ricardo Tonelli, que dice: invocación es "la actitud existencial del que vive el fragmento de existencia del que es protagonista, tendido a, con una esperanza actuante, hacia una razón del sentido que reconoce no poseer". Todo hombre lleva dentro de sí un hambre de absoluto, pero solo no puede saciar este hambre. La única posibilidad es que el Absoluto se haga el encontradizo con el hombre y el hombre se abandone a él. Quizás se cansa de escuchar y de entender bien. Ilustraré la definición de sentido existencial, con esta historia de Bruno Ferrero, de aquella familia que debe escapar de casa una noche porque se ha declarado un incendio en su casa. Papá, mamá y los niños salen lo más rápido posible, pero cuando están fuera ven un gran humo y no ven al niño más pequeño. El papá llama a este niño y, finalmente se oye una voz desde el desván, el niño llama "Papá, papá", y el papá le dice "Échate abajo", y el niño "pero no veo nada", "te veo yo, échate abajo". Si cerramos la moviola en el momento en el que este niño está a punto de decidirse a bajar, tiene el fuego a sus espaldas: no puede volver adentro; delante tiene el vacío, el humo: no ve nada, la oscuridad. ¿Qué es lo que lo decidirá a lanzarse? No es el ver a su padre, sino saber que su padre está allí,. "Te veo yo, échate abajo".

Esta es la aventura de la fe. La vocación es la fe, si no ¿qué cosa es? Esto debe garantizar una comunidad cristiana. La educación en la $\mathrm{fe}$, o sea en el fiarse, el confiarse, el lanzarse, no porque tu ves, sino porque crees que aunque no esté la red de protección, allí están sin 
embargo los brazos fuertes de papá, de este Dios Abba, que no dejará que te estrelles en el vacío.

\section{Algunas pistas de concretización}

En primer lugar: es necesario repetir con palabras nuevas pobreza, castidad, obediencia. La pobreza me libera del deseo de poseer y me abre a la alegría del compartir. La castidad no apaga la afectividad, sino que la mantienen viva. La obediencia no reprime la libertad, sino la mantiene en alto.. Don Milani: "Cuando uno regala su libertad es más libre que uno que está obligado a contenerla"

En segundo lugar: Las experiencias asociativas, en las cuales el fin está claro y totalmente perceptible, son útiles y para muchos jóvenes indispensables; son pequeños aprendizajes en los que se mide, en los que se sostiene un camino que tiene un mínimo de continuidad, de orientación constante hacia un objetivo, de prueba de la propia capacidad de cumplirlo.

En tercer lugar: La escucha de la Palabra, ayudar a los jóvenes a orar, a descubrir la belleza de la oración. Pero ¿dónde está escrito que los jóvenes no vienen? ¿Cómo es posible que los jóvenes no se dejen encantar, fascinar por la figura de Jesús? La escucha de la Palabra, si no es por rutina o por estética o por los filólogos, sino capaz de interpretar la vida, ayuda a encontrar puntos de referencia para la decisión. A ella está ligada la plegaria y el contacto (de la lectura) de la vida de los santos. Los religiosos y las religiosas a este respecto tienen muchas posibilidades de presentar con los destellos de una respuesta a la llamada de Dios en la vida de sus santos fundadores. Obviamente, una vida de la que se ha dejado contagiar.

Por último. Una guía espiritual que comprende y relanza en el interesado la decisión, sin crear soledad y mucho menos dependencia; capaz de proponer experiencias significativas y casi simuladoras del futuro camino que se tiene en la cabeza recorrer. Con frecuencia es suficiente arbitrar lugares que permitan un diálogo espiritual, abiertos a los horarios de los jóvenes, como monasterios y conventos. Lugares de fuerte experiencia religiosa para hacer entender que son otros caminos, los caminos de Dios para (salir al encuentro). 